\title{
21. ANALYSIS OF ORGANIC MATTER IN SEDIMENT CORES FROM THE MOROCCAN BASIN, DEEP SEA DRILLING PROJECT SITES 415 AND 416
}

\author{
George E. Claypool and Jeffrey P. Baysinger, U.S. Geological Survey, Denver, Colorado
}

\begin{abstract}
SUMMARY
Organic matter in turbidite sediments of the Moroccan Basin appears to be derived primarily from terrigenous sources. Sediments with greater than 0.3 per cent organic carbon also contain a variable component of organic matter produced in the water column at the site of deposition. The organic matter shows evidence of progressive thermal alteration with increasing depth of burial, but even in the deepest sample (1532 m) it is still immature with respect to the degree of thermal alteration required to attain advanced stages of the petroleum hydrocarbon generation process.
\end{abstract}

\section{DISCUSSION}

Eight samples collected during DSDP-IPOD Leg 50 were analyzed by organic-geochemistry techniques that are routinely employed for petroleum-source-rock evaluation. One sample in Hole 415 at relatively shallow depth of burial $(210 \mathrm{~m})$ was from an interval described as lower Miocene chalk. The remaining seven samples, from Hole 416A, are Cretaceous turbidites that are among the most deeply buried (1180-1532 m) rocks sampled by DSDP.

The results of our analyses are presented in Table 1 . Three general types of analyses were performed:

1. Determination of total organic carbon by a wet oxidation technique slightly modified from Bush (1970).

2. Thermal-evolution analysis as described previously (Claypool and Baysinger, 1978), except that temperatures of maximum pyrolysis yield reflect estimated rock temperatures rather than furnace temperatures, and hydrocarbon yields are determined on the basis of calibration of the detector using a synthetic $n-C_{20}$ standard rather than a natural-rock standard.

3 . Soxhlet extraction with chloroform and characterization of the bitumen by column and gas chromatography as described elsewhere (Claypool et al., 1978).

All of these samples contain relatively little total organic matter. Measured organic-carbon values range from 0.07 to 0.89 per cent. For purposes of general discussion, the samples are divided into two groups, either greater or less than 0.3 per cent organic-carbon content. Four samples have less than 0.3 per cent organic carbon: the shallow chalk sample from Hole 415, and the shallowest and the two deepest samples from the Cretaceous turbidite sequence in Hole 416A. These samples all have similar qualitative organic geochemical characteristics, in addition to having a low organic-carbon content. They are also lowest in the proportion of hydrocarbons relative to organic carbon $(\mathrm{HC} / \mathrm{C}$ ratios of 0.4 per cent or less). Extractable organic matter is relatively more enriched in saturated hydrocarbons (especially that of the two deepest samples) compared with the samples that have greater than 0.3 per cent organic carbon. The saturated-hydrocarbon distributions of the four leanest samples also have similar qualitative characteristics; i.e., the gas-chromatography baseline is relatively flat, odd-numbered $n$-alkanes from $n-\mathrm{C}_{25}$ to $n-\mathrm{C}_{33}$ being the major constituents (Figure 1a, $\mathrm{b}, \mathrm{g}, \mathrm{h})$. The gas-chromatography humps in Figures $1 \mathrm{~g}$ and $1 \mathrm{~h}$ are caused more by background and expansion of the electronic signal, to produce a comparable chromatogram for these samples in which the absolute quantity of extractable hydrocarbon was extremely low, than by the presence of a complex, unresolvable mixture of hydrocarbons.

Thermal analysis of these leaner samples (415-4-2, 103-106 cm, 416A-9-2, 122-132 cm, 416A-42-2, 22-32 $\mathrm{cm}, 416 \mathrm{~A}-48-2,104-114 \mathrm{~cm}$ ) confirms their low content of organic matter and indicates that the organic matter present is relatively inert with respect to pyrolytic hydrocarbon generation. In other words, not only is the organic content in these samples low, but it is not of the type that is efficiently converted to hydrocarbons by heating. This is indicated by the pyrolytic hydrocarbonto-organic-carbon ratios of $8.7,7.3$, and 2.0 per cent for the samples from Hole 416A at depths of 1180,1475 , and 1532 meters, respectively. Thermograms for these samples show a single pyrolysis peak with maxima at the temperatures reported in Table 1 . The shallow $(210 \mathrm{~m})$ chalk sample from Hole 415 has a somewhat higher pyrolytic hydrocarbon-to-organic-carbon ratio $(12.7 \%)$ and produces a thermogram of distinctly different shape in which two fused peaks appear to represent the pyrolysis of solid organic matter. The temperature of maximum pyrolysis yield reported in Table 1 is for the second peak. We do not know if this double pyrolysis peak, suggesting a mixture of two different types of solid organic matter, is primarily associated with a lower-temperature history and shallower depth of burial $(210 \mathrm{~m}$ vs. $>1180 \mathrm{~m})$ or with contrasting lithologies (chalk vs. turbidite).

The remaining four samples that have greater than 0.3 per cent organic-carbon content (at 1230, 1266, 1305 , and $1362 \mathrm{~m}$ ) also have subtle but significant differences in the content and qualitative character of extractable organic matter and its behavior upon thermal analysis. The extractable hydrocarbon content of these samples is higher (ranging from 20 to $74 \mathrm{ppm}$ ) than in those samples with less than 0.3 per cent organic carbon, which have concentrations ranging from 2 to 6 
TABLE 1

Geochemical Analyses of Moroccan Basin Sediments, DSDP Sites 415 and 416

\begin{tabular}{|c|c|c|c|c|c|c|c|c|c|c|c|c|}
\hline \multirow[b]{2}{*}{$\begin{array}{c}\text { Sample } \\
\text { (Interval in } \mathrm{cm})\end{array}$} & \multirow[b]{2}{*}{$\begin{array}{l}\text { Depth } \\
\text { (m) }\end{array}$} & \multirow[b]{2}{*}{$\begin{array}{l}\text { Organic } \\
\text { Carbon } \\
\text { (wt. \%) }\end{array}$} & \multicolumn{4}{|c|}{ Thermal Analysis } & \multicolumn{6}{|c|}{ Solvent Extraction } \\
\hline & & & $\begin{array}{c}\text { Total } \\
\text { Pyrolitic } \\
\text { Hydrocarbon } \\
\text { Yield } \\
\text { (wt. \%) }\end{array}$ & $\begin{array}{c}\text { Volatile } \\
\text { Hydrocarbon } \\
\text { Content } \\
\text { (ppm) }\end{array}$ & $\begin{array}{c}\text { Pyrol. HC } \\
\text { Organic } \\
\text { Carbon } \\
(\%)\end{array}$ & $\begin{array}{l}\text { Temp. of } \\
\text { Max. Pyrol } \\
\text { Yield } \\
\left({ }^{\circ} \mathrm{C}\right)\end{array}$ & $\begin{array}{l}\text { Bitumen } \\
(\mathrm{ppm})\end{array}$ & $\begin{array}{l}\text { Total } \\
\text { Hydro- } \\
\text { Carbons } \\
\text { (ppm) }\end{array}$ & Sat./Arom. & $\underset{(\%)}{\text { Hydc./Org. C }}$ & $\begin{array}{l}\text { Hydc./Bit. } \\
(\%)\end{array}$ & CPI \\
\hline \multicolumn{13}{|c|}{ Hole $415\left(31^{\circ} 01.72^{\prime} \mathrm{N} 11^{\circ} 39.11^{\prime} \mathrm{W}\right)$} \\
\hline $4-2,103-106$ & 210 & 0.13 & 0.016 & 22 & 12.7 & 440 & 8 & 2 & 0.92 & 0.15 & 25 & 4.6 \\
\hline \multicolumn{13}{|c|}{ Hole 416A $\left(32^{\circ} 50.18^{\prime} \mathrm{N} \quad 10^{\circ} 48.06^{\prime} \mathrm{W}\right)$} \\
\hline $\begin{array}{l}9-2,122-132 \\
14-4,98-111 \\
18-3,119-132 \\
23-3,146-150 \\
28-4,100-112 \\
42-2,22-32 \\
48-2,104-114\end{array}$ & $\begin{array}{l}1180 \\
1230 \\
1266 \\
1305 \\
1362 \\
1475 \\
1532\end{array}$ & $\begin{array}{l}0.28 \\
0.47 \\
0.52 \\
0.89 \\
0.37 \\
0.07 \\
0.20\end{array}$ & $\begin{array}{l}0.028 \\
0.041 \\
0.068 \\
0.201 \\
0.031 \\
0.005 \\
0.004\end{array}$ & $\begin{array}{r}9 \\
14 \\
13 \\
37 \\
10 \\
8 \\
5\end{array}$ & $\begin{array}{r}8.7 \\
8.8 \\
13.2 \\
22.6 \\
8.5 \\
7.3 \\
2.0\end{array}$ & $\begin{array}{l}464 \\
438 \\
460 \\
452 \\
460 \\
450 \\
464\end{array}$ & $\begin{array}{r}20 \\
44 \\
56 \\
180 \\
55 \\
6 \\
7\end{array}$ & $\begin{array}{r}6 \\
20 \\
20 \\
74 \\
30 \\
3 \\
6\end{array}$ & $\begin{array}{l}0.91 \\
0.90 \\
0.66 \\
0.76 \\
0.92 \\
1.0 \\
3.6\end{array}$ & $\begin{array}{l}0.20 \\
0.42 \\
0.38 \\
0.83 \\
0.81 \\
0.4 \\
0.3\end{array}$ & $\begin{array}{l}28 \\
46 \\
36 \\
41 \\
55 \\
45 \\
84\end{array}$ & $\begin{array}{l}3.0 \\
3.8 \\
3.1 \\
2.4 \\
3.6 \\
2.6 \\
2.7\end{array}$ \\
\hline
\end{tabular}

ppm. The proportion of organic carbon present as extractable hydrocarbons is also higher $(0.4$ to $0.8 \%)$ in the samples that have more than 0.3 per cent organic carbon. The samples richer in organic carbon, however, especially the two richest, contain relatively less saturated hydrocarbon. In addition, these saturated hydrocarbons have a more complex distribution, as indicated by gaschromatography analysis (Figure 1c, d, e, f). These samples all have definite humps of unresolved compounds centered in the $n-\mathrm{C}_{17}$ and $n-\mathrm{C}_{29}$ regions. The heavy $\left(n-\mathrm{C}_{25}\right.$ to $\left.n-\mathrm{C}_{33}\right) n$-alkanes are still the most prominent compounds in all the samples except the richest sample, 416A-23-3, 146-150 cm (Figure 1c), which has 0.89 per cent organic carbon. This sample contains compounds that produce major peaks between $n-\mathrm{C}_{27}$ and $n-\mathrm{C}_{28}$ and that are co-eluted with $n$ - $\mathrm{C}_{30}$. Unsaturated compounds (cholest-5-ene and an unidentified $\mathrm{C}_{29}$ sterene) with the same relative retention times were found to uniquely characterize presumed autochthonous organic matter in Pleistocene lacustrine marls in the Black Sea basin (Anders et al., 1978). Although it seems unlikely that sterenes would be preserved in Cretaceous turbidites, the general distribution, if not of these specific compounds, suggests that the major component of the organic matter in this sample was produced at the site of deposition rather than washed in with the turbidites. Chromatograms $\mathrm{d}$ and $\mathrm{f}$ (Figure 1) suggest that lower concentrations of the same kinds of compounds are present in Samples 416A-18-3, 119-132 cm and 416A$28-4,100-112 \mathrm{~cm}$.

Thermal analysis of samples containing more than 0.3 per cent organic carbon confirmed the increased contents of organic material in these samples. In addition, the two richest samples $(416 \mathrm{~A}-18-3,119-132 \mathrm{~cm}$ and $416 \mathrm{~A}-23-3,146-150 \mathrm{~cm}$ ) had significantly higher pyrolitic hydrocarbon yields relative to organic carbon. This means not only that more organic matter is preserved in these samples, but also that the organic matter present is more readily converted to hydrocarbons upon heating.

As was the case with DSDP sediments investigated previously, these samples all appear to be thermally immature, to a greater or lesser degree, with respect to the temperature history required to produce an indigenous assemblage of petroleum-like hydrocarbons. Composition of the extractable organic matter, however, shows significant change with increasing depth of burial. The estimated odd-over-even $n$-alkane predominance, expressed as carbon-preference index (CPI, Bray and Evans, 1961), decreases from a value of 4.6 in Sample 415-4-2, 103-106 cm, from a depth of 210 meters, to 3.0 in Sample 416A-9-2, 122-132 cm, from a depth of 1180 meters, to a value of 2.6 in Sample 416A-42-2, 22-32 $\mathrm{cm}$, a depth of 1475 meters. These values are significantly higher than the value $C P I=1$, which characterizes the great majority of crude oils and hydrocarbon extracts of petroleum source rocks. The CPI values may not change as rapidly with increased burial temperature in organically lean rocks as they would in rocks richer in organic matter. This is because thermal alteration of sedimentary organic matter causes CPI to approach a value of 1 by two mechanisms: (a) dilution with newly formed $n$-alkanes; and (b) thermal cracking of preexisting $n$-alkanes. Much greater time-temperature equivalents are probably required for thermal cracking than for formation of $n$-alkanes from labile nonhydrocarbon precursors such as organic acids, alcohols, and esters. A sediment lacking in these $n$-alkane precursors may undergo slower change in CPI for equivalent thermal history than sediments richer in such precursor molecules.

Geochemical properties thought to be sensitive to thermal maturity are plotted in Figure 2. These are CPI, hydrocarbon content relative to both organic carbon and bitumen contents, and the temperature of maximum pyrolysis yield during thermal analysis. Except for the hydrocarbon percentage of organic carbon, which seems to reflect primarily the type of organic matter (i.e., allochthonous vs. autochthonous), the other maturity indicators change more or less in the same direction and to about the same degree as the CPI values.

In summary, analysis of eight samples from two holes of DSDP-IPOD Leg 50 shows that extractable organic matter in samples with less than 0.3 per cent organic carbon is dominated by higher-plant-wax $n$ - 


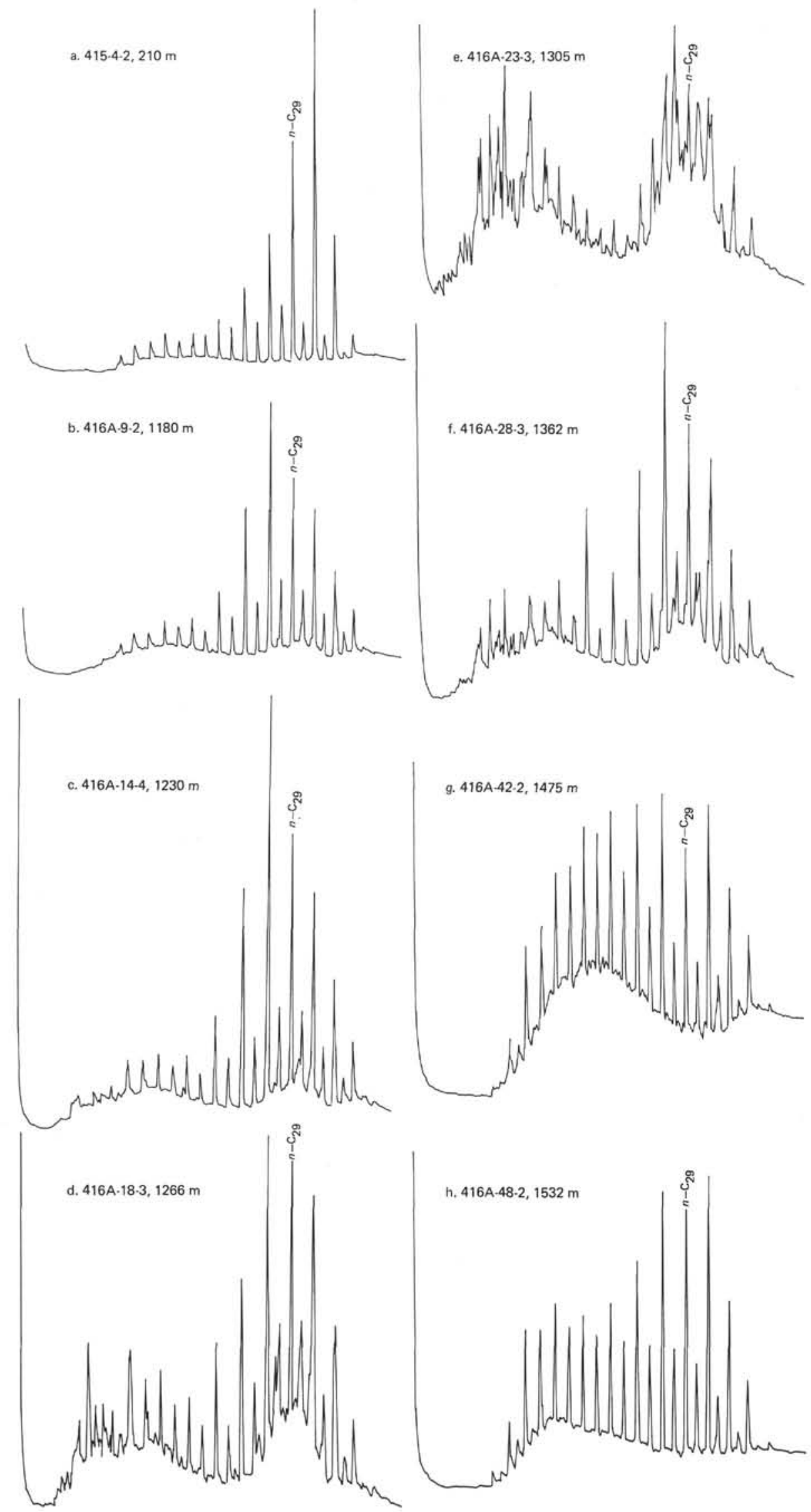

Figure 1. Gas chromatographic analysis of saturated hydrocarbons, Leg 50 samples. 


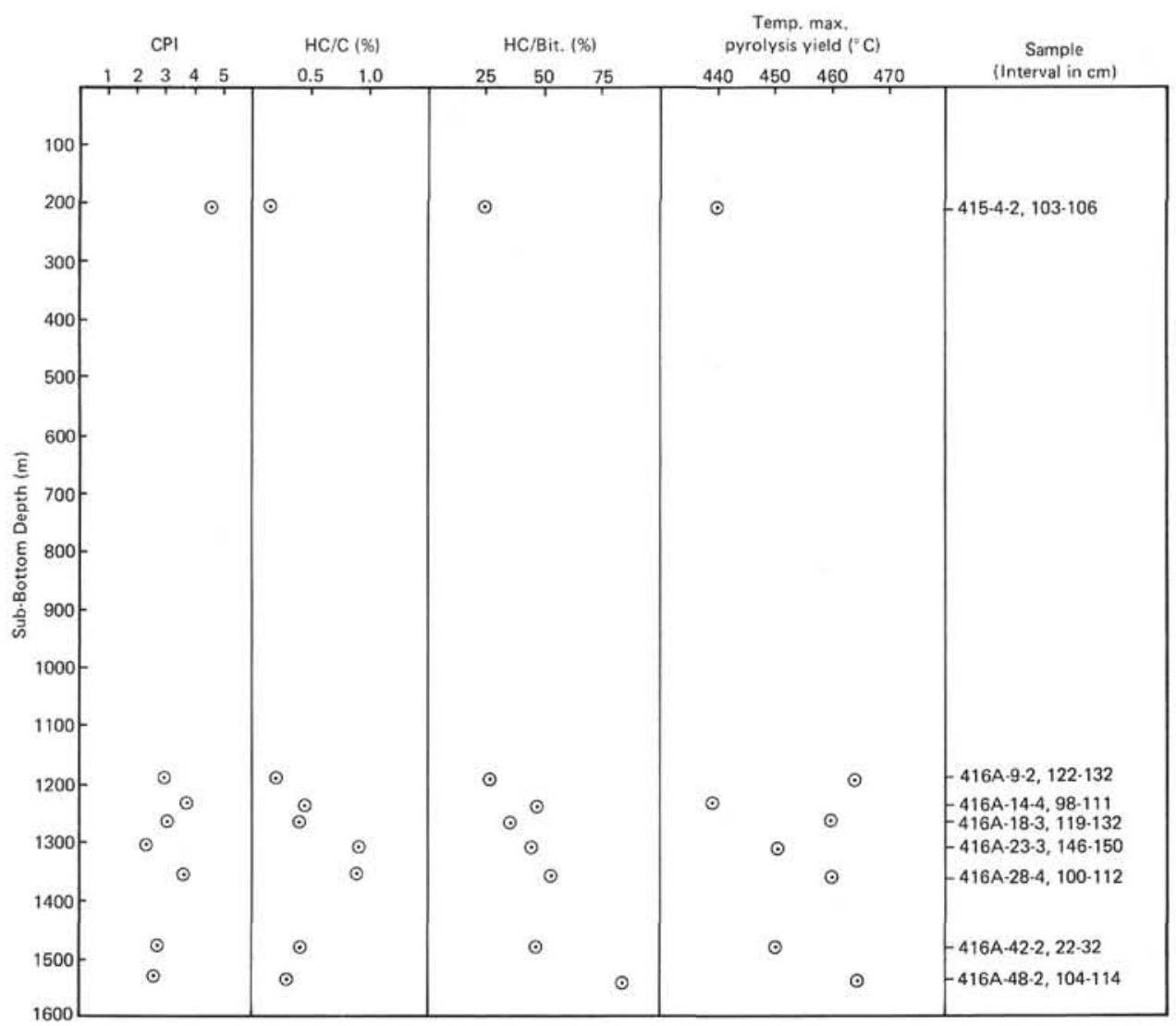

Figure 2. Geochemical properties sensitive to degree of thermal alteration (maturity).

alkanes. These compounds are resistant to metabolic decomposition and probably survived lengthy transport along with other terrigenous debris. Samples with greater than 0.3 per cent organic carbon likewise contain the terrigenous component marked by plant-wax $n$-alkane compounds, but also have an additional organic component that may represent productivity in the water column at the site of deposition. The organic matter shows evidence of progressive thermal alteration with increased depth of burial, but the degree of thermal alteration in the deepest samples appears to be less than that which would be necessary to produce a mature petroleum-like assemblage of hydrocarbons, even if petroleum source materials had been more abundant in these sediments.

\section{ACKNOWLEDGMENTS}

We thank Keith A. Kvenvolden and Peter A. Scholle of the U.S. Geological Survey for reviewing this manuscript.

\section{REFERENCES}

Anders, D. E., Claypool, G. E., Lubeck, Sister C. M., and Patterson, J. M., 1978. Preliminary results, organic geo- chemical investigation of Black Sea sediments - Deep Sea Drilling Project Leg 42B. In Ross, D. A., Neprochnov, Y., et al., Initial Reports of the Deep Sea Drilling Project, v. 42: Washington (U.S. Government Printing Office), p. 755-763.

Bray, E. E. and Evans, E. D., 1961. Distribution of $n$-paraffins as a clue to recognition of source beds, Geochim. Cosmochim. Acta, v. 22 , p. 2-15.

Bush, P. R., 1970. A rapid method for determination of carbonate carbon and organic carbon, Chem. Geol., v. 6, p. 59-62.

Claypool, G. E. and Baysinger, J. P., 1978. Thermal analysis/ pyrolysis of Cretaceous sapropels - DSDP Leg 44, Hole 391C, Blake-Bahama Basin. In Benson, W. E., Sheridan, R. E., et al., Initial Reports of the Deep Sea Drilling Project, v. 44: Washington (U.S. Government Printing Office), p. 635-637.

Claypool, G. E., Love, A. H., and Maughan, E. K., 1978. Organic geochemistry, incipient metamorphism, and oil generation in black shale members of Phosphoria Formation, western interior United States, Am. Assoc. Petrol. Geol. Bull., v. 62, p. 98-120. 